\title{
A Survey of Factors on Design for Manufacture of Chemical Fertilizer Granulating Machine
}

\author{
J. A. Ikimi, W. E. Odinikuku, and T. B. Adeleke
}

\begin{abstract}
The design for manufacturing of granulating machines to produce fertilizer granules in small scale using locally available materials is often challenging and this results in low fertilizer usage among Nigerian farmers when compared with the world's average usage. A lot of factors are associated with chemical fertilizer granulating machine, and it is necessary to examine and understand the interplay among these factors. This study weighs up a number of variables that relates with the design and usage of chemical fertilizer granulating machine and offers increased insight and awareness about their insidiousness. The study employed a survey approach, using the Rensis Likert's attitudinal scale, to generate respondents' data matrix that was analyzed with Principal Component Analysis (PCA), and which was facilitated by statistiXL software. Kendall's Coefficient of Concordance (KCC) was used to rank the thirty two (32) identified variables and PCA was thereafter deployed to ascertain the degree of interplay among the variables. Results obtained by KCC suggested that judges ranking were consistent as there was sufficient evidence to reject the null hypothesis Also, PCA was indicating parsimony in data reduction from 32 variables to mere five. The result established five principal factors creatively labeled Miscellany Components, Technical Considerations, Granulation Efficiency, Agricultural National policy and Biophysical Elements. The most influential variable by its factor loading of $\mathbf{0 . 8 9 4}$ is Agricultural National policy. A gamut of variables which seem to affect chemical fertilizer granulating machine has been examined. This has helped in discerning similarities in dissimilarities.
\end{abstract}

Index Terms - Chemical Fertilizer, Scree Plot, Hypotheses, Granulating.

\section{INTRODUCTION}

The state of food insecurity in Nigeria has become so deplorable that we are called a "food deficit" country in the world. Our agriculture is said to be characterized by low productivity, low technology, and high labor intensity [1]. A body of literature on fertilizers has addressed the need for individuals and organizations to get involved in its production. For instance, [2] called for the involvement and encouragement of private individuals who know how to tap our abundant natural resources in the production of fertilizers. According to [4], one should know that having fertilizers in granules control dust from forming, decrease transportation costs and losses, reduce the risk of freezing and caking. Advance technology of forming inorganic fertilizer granules employed in large-scale production are reported by [5] and [6]. In Nigeria, little appears to be known on the appropriate technology for small-scale production of inorganic fertilizers

Submitted on May 15, 2021.

Published on June 25, 2021.

J. A. Ikimi, Department of Mechanical Engineering, Petroleum Training Institute, Effurun, Delta State, Nigeria.

(e-mail: Jephtahikimi@gmail.com) in granules. This has resulted to a huge lack of fertilizer or fertilizer machines for use by the local farmer in the absence of government subsidized commercial chemical fertilizer. There is a concomitant overutilization of the arable land which leads to poor crop yields for a given space. The need therefore to boost land fertility through the use of both organic and chemical fertilizers has been canvassed [6] and [7]. The arable farmland of the country has remained highly uncultivated because the government is not involved in large scale farming as was the case in the colonial era. The need therefore to boost land fertility through the use of both organic and inorganic fertilizers is desirable. More so is this necessary because the application of fertilizer in Nigeria is very low when compared with the average application in the world as stated by [8]. Granulation as a process of improving flowability and appearance of fertilizers is one of the major processes involved in fertilizer production which transforms fine powders into granules in order to improve the characteristics of materials used as fertilizers and as a means of protecting the end users from hazards such as dust, [9]. Efforts made by past and present government through the combine provisions of importing and producing fertilizer and supply/distribution of fertilizer to farmers at subsidized prices to boost farmers' productivity has not been very successful. The result is that fertilizer usage among Nigerian farmers has remained very low (13 kg/hectare) as compared with the world's average usage $(100 \mathrm{~kg} / \mathrm{hectare})$. It becomes urgent therefore to meet this huge demand through the design and construction of fertilizer granulating machine to produce fertilizer granules in small-scale using available local materials. There is drought of information vis-à-vis the technology to develop and produce fertilizer in small scale using locally sourced materials. Hence, appropriate technology of producing fertilizer in the most acceptable way have to be explored there after designed and constructed with the acquired and previous engineering know-how. A novel application of two statistical techniques namely Kendall Coefficient of Concordance and Principal Component are novel statistical tools used in this study. PCA is a dimensional-reduction tool that can be used to reduce a large set of variables to a small set that still contains most of the information in the large set. The goal is dimension reduction, and it selects a subset of variables from a larger set, based on which original variables have the highest correlations with the principal component. In the context of management and factorial analysis [10] asserts that a trivial fraction of the entirety is accountable for a great quantity of the total result

W. E. Odinikuku, Department of Mechanical Engineering, Petroleum Training Institute, Effurun, Delta State, Nigeria.

(e-mail: williamsodinikuku@gmail.com)

T. B. Adeleke, Department of Production Engineering, University of Benin, Benin City, Edo State, Nigeria.

(e-mail: tunde.adeleke@eng.uniben.edu). 
There is gamut of variables that individually and collectively affect the design, manufacture and usage of chemical fertilizer granulating machine. These variables need to be analyzed collectively in order to have a systemic understanding of them.

\section{MethodologY}

\section{A. Kendall's Coefficient of Concordance}

An exploratory survey of the factors was conducted using well-crafted questionnaires. 32 variables were used to craft questionnaires scaled with 5-point linkert's attitudinal scale and administered to over 100 respondents. Also, 13 judges knowledgeable in the area were required to rank variables in order of importance from the most to the least important and respondents' scores were transposed into matrix variables.

Kendall's Coefficient of Concordance (W), can be calculated using (1):

$$
W=\frac{S}{\frac{1}{12} K^{2}\left(N^{3}-N\right)}
$$

where,

$$
S=\sum\left(R_{j}-\frac{\sum R_{j}}{N}\right)^{2}
$$

$\mathrm{Rj}=$ Column sum of ranks;

$\mathrm{N}=$ Total number of Variables;

$\mathrm{S}=$ Variance;

$\mathrm{K}=$ Number of experts.

\section{B. Principal Component Analysis}

The Principal Component Analysis is one of the methods of factor Analysis. Respondents' scores were collated as data matrix. The data matrix was fed into StatistiXL software that gave the outputs which include scree plot, factor plot, varimax rotated factor loadings amongst others.

$$
\mathrm{rij}=\frac{\sum x y}{\sqrt{\left(\sum x^{2}\right)\left(\sum y^{2}\right)}}
$$

where

$$
\mathrm{x}=\mathrm{xij}-\bar{x} \mathrm{ij}
$$$$
\mathrm{y}=\mathrm{yij}-\bar{y} \mathrm{ij}
$$$$
\bar{x} \mathrm{ij}=\frac{\sum_{i=1}^{N} x i j}{N}
$$$$
\bar{y} \mathrm{ij}=\frac{\sum_{i=1}^{N} y \mathrm{ij}}{N}
$$

$\mathrm{N}=\mathrm{nj}=\mathrm{imax}$

$$
\mathrm{J}=\mathrm{jmax}
$$

\section{RESUlT AND DISCUSSION}

\section{A. Results of Kendall's Coefficient of Concordance}

The test hypotheses are:

$H_{o}$ : The ranking of the 13 judges is not coherent.

$H_{1}$ : The ranking of the 13 judges is coherent.

Therefore, to calculate for:

$$
\begin{aligned}
\chi^{2}= & K(\mathrm{~N}-1) \mathrm{W} \\
& =13(32-1) 0.466 \\
& =13(31) 0.466 \\
& =187.79 \\
\chi^{2} \text { cal. } & =187.79
\end{aligned}
$$

Therefore, to calculate for the $\chi^{2} t a b$ because we need to plot the tabulated values and also the calculated value and then apply our decision rule in order to get a reliable conclusion.

$$
\chi^{2} \operatorname{tab}_{0.01,32}
$$

From our chi-square table, $\chi^{2}$ tab whereby -1 is introduced which signify the degree of freedom.

$$
\chi_{0.01,32}^{2}
$$

Note: our alpha level $(\propto)=0.01$

$$
\chi_{0.01,31}^{2}=79.65
$$

The coefficient of concordance was computed as $\mathrm{W}=0.54$, which is a middling.

From our decision rule which say:

$$
\begin{aligned}
& \text { Reject } H_{o} \text { if } F_{c a l}>F_{t a b} \\
& \text { Accept } H_{o} \text { if } F_{c a l}<F_{t a b}
\end{aligned}
$$

And $79.65<187.79$

Since our $F_{c a l}>F_{t a b}$, this concludes that experimental data do not furnish enough evidence for us to accept the null hypothesis claim which says experts ranking were at disconcordance. This then implies that experts ranking is at concordance. The chi square test at 0.01 significant levels shows the critical values is 79.65 . This made us to not accept the null hypothesis that the judges ranking is discordant. Our conclusion therefore is that the judges use the same criteria for the ranking of all the scale items. Consequently, the statistical tool was able to rank the scale items in merit order of sequentially and they are depicted hereunder in Table I.

The import of this ordering of the variables by the judges enabled us to know that Agricultural national policy is considered most important in the use of fertilizer granulating machine. 


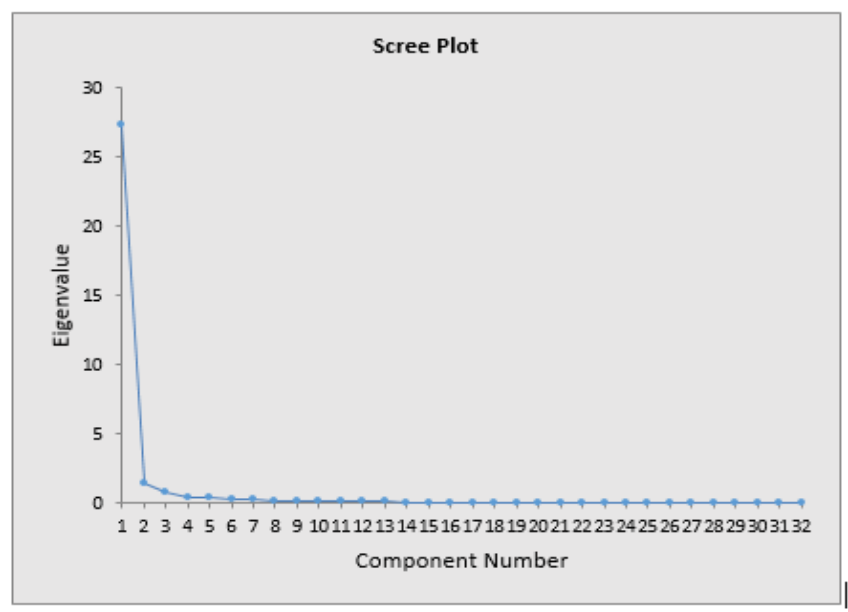

Fig. 1. Scree plot.

TABLE I: MERIT ORDER SEQUENTIALITY OF THE 32 VARIABLES

\begin{tabular}{cccccc}
\hline S/No & $R_{j}$ & Variables & S/No & $R_{j}$ & Natural deposits \\
\hline 1 & 76 & Agricultural national policy & 17. & 207 & Granules spill rate \\
2 & 80 & Design Considerations & 18. & 213 & High power requirements \\
3 & 83 & Machine Production Cost & 19. & 238 & Soil fertility \\
4 & 84 & Availability of Raw materials & 20. & 254 & 21. \\
5 & 92 & High cost of maintenance & 264 & Granulation process efficiency \\
6 & 102 & Fertilization Demand & 22. & 270 & Fertilizer production know-how \\
7 & 145 & Associated Legislation and Regulation & 23. & 274 & Granulometric content \\
8 & 149 & Production of Biofertilizers & 24. & 275 & Physical-chemical properties \\
9 & 153 & Optimum Granules Formation & 25. & 280 & Fertilizer granulation disc \\
10 & 164 & Preference for Pelletizer & 26. & 281 & Atmospheric conditions \\
11 & 167 & Scarcity of Inorganic fertilizer & 27. & 285 & Granulation method \\
12 & 172 & Lack of indigenous Technology & 28. & 306 & Safety considerations \\
13 & 173 & Enhanced efficiency fertilizer & 29. & 312 & Ease of use \\
14 & 195 & Environmental issues & 30. & 335 & Complexity of design \\
15 & 196 & Level of farmers productivity & 31. & 337 & Characteristics of granules \\
16 & 207 & Lack of innovation & 32 & 340 & Equipment type \\
\hline
\end{tabular}

TABLE II: VARIMAX ROTATED FACTOR LOADINGS

\begin{tabular}{|c|c|c|c|c|c|c|}
\hline $\mathrm{S} / \mathrm{N}$ & Variable & Factor 1 & Factor 2 & Factor 3 & Factor 4 & Factor 5 \\
\hline 1 & Agricultural national policy & 0.516 & 0.385 & 0.316 & 0.894 & 0.097 \\
\hline 2 & Design Considerations & 0.815 & 0.463 & 0.228 & 0.057 & 0.103 \\
\hline 3 & Machine Production Cost & 0.452 & 0.776 & 0.255 & 0.236 & 0.134 \\
\hline 4 & Availability of Raw materials & 0.594 & 0.437 & 0.380 & 0.266 & 0.333 \\
\hline 5 & High cost of maintenance & 0.530 & 0.742 & 0.207 & 0.137 & 0.126 \\
\hline 6 & Fertilization Demand & 0.540 & 0.724 & 0.300 & 0.142 & 0.067 \\
\hline 7 & Associated Legislation and Regulation & 0.811 & 0.465 & 0.208 & 0.150 & 0.144 \\
\hline 8 & Production of Biofertilizers & 0.543 & 0.737 & 0.222 & 0.185 & 0.081 \\
\hline 9 & Optimum Granules Formation & 0.739 & 0.376 & 0.245 & 0.359 & 0.033 \\
\hline 10 & Preference for Pelletizer & 0.577 & 0.455 & 0.458 & 0.193 & 0.181 \\
\hline 11 & Scarcity of Inorganic fertilizer & 0.830 & 0.425 & 0.211 & 0.165 & 0.144 \\
\hline 12 & Lack of indigenous Technology & 0.723 & 0.344 & 0.355 & 0.268 & 0.113 \\
\hline 13 & Enhanced efficiency fertilizer & 0.405 & 0.597 & 0.619 & 0.223 & 0.114 \\
\hline 14 & Environmental issues & 0.382 & 0.793 & 0.312 & 0.246 & 0.146 \\
\hline 15 & Level of farmers productivity & 0.411 & 0.826 & 0.260 & 0.107 & 0.121 \\
\hline 16 & Lack of innovation & 0.819 & 0.433 & 0.214 & 0.192 & 0.109 \\
\hline 17 & Natural deposits & 0.424 & 0.500 & 0.361 & 0.093 & 0.626 \\
\hline 18 & Granules spill rate & 0.426 & 0.667 & 0.238 & 0.115 & 0.149 \\
\hline 19 & High power requirements & 0.787 & 0.480 & 0.270 & 0.100 & 0.134 \\
\hline 20 & Soil fertility & 0.790 & 0.498 & 0.233 & 0.101 & 0.078 \\
\hline 21 & Granulation process efficiency & 0.771 & 0.384 & 0.264 & 0.263 & 0.244 \\
\hline 22 & Fertilizer production know-how & 0.506 & 0.776 & 0.212 & 0.157 & 0.089 \\
\hline 23 & Granulometric content & 0.461 & 0.384 & 0.561 & 0.233 & 0.123 \\
\hline 24 & Amount of rainfall & 0.392 & 0.469 & 0.383 & 0.176 & 0.598 \\
\hline 25 & Fertilizer granulation disc & 0.470 & 0.786 & 0.234 & 0.124 & 0.106 \\
\hline 26 & Atmospheric conditions & 0.783 & 0.380 & 0.267 & 0.254 & 0.031 \\
\hline 27 & Granulation method & 0.312 & 0.599 & 0.694 & 0.176 & 0.105 \\
\hline 28 & Safety considerations & 0.395 & 0.721 & 0.334 & 0.165 & 0.174 \\
\hline 29 & Ease of use & 0.667 & 0.344 & 0.374 & 0.320 & 0.126 \\
\hline 30 & Complexity of design & 0.398 & 0.710 & 0.419 & 0.204 & 0.124 \\
\hline 31 & Characteristics of granules & 0.418 & 0.789 & 0.297 & 0.232 & 0.133 \\
\hline 32 & Equipment type & 0.725 & 0.567 & 0.182 & 0.168 & 0.022 \\
\hline
\end{tabular}




\section{B. Factor Interpretation}

The PCA adopted with the aid of StatistiXL software, generated five (5) clusters or platoons. A principal factor embodying fourteen (14) variables which were creatively labelled; Notable factors in this cluster are design considerations, associated legislation and regulation, scarcity of inorganic fertilizer and lack of innovation with factor loadings of $0.815,0.811,0.830$ and 0.879 . These are important scale items that affect the design of a fertilizer granulating machine. The rest variables under this factor in themselves are also important and should be looked at accordingly.

TABLE III: TECHNICAL CONSIDERATIONS

\begin{tabular}{ccc}
\hline \multicolumn{3}{c}{ Clusters 2(Factor 2): Technical Considerations } \\
\hline S/N & Variable description & Factor loading \\
\hline 3 & Machine Production Cost & 0.776 \\
5 & High cost of maintenance & 0.742 \\
6 & Fertilization Demand & 0.724 \\
13 & Enhanced efficiency fertilizer & 0.597 \\
14 & Environmental issues & 0.793 \\
15 & Level of farmers productivity & 0.826 \\
18 & Granules spill rate & 0.607 \\
22 & Fertilizer production know-how & 0.776 \\
25 & Fertilizer granulation disc & 0.786 \\
28 & Safety considerations & 0.721 \\
30 & Complexity of design & 0710 \\
31 & Characteristics of granules & 0.789 \\
\hline
\end{tabular}

Cluster 2 is creatively labelled Technicalities. The factor loadings are all positive. The cluster also encapsulates a wide variety of factors. Of note amongst them are machine production costs, environmental issues, level of farmer's productivity with factor loadings of $0.776,0.793$ and 0.826 . The cost of a granulating machine will determine if it can be easily bought by farmers. Relatedly, how productive a farmer is will also determine if he should purchase the granulating machine or look for other cheap means or source of fertilizer application.

TABLE IV: GRANULATION EFFICIENCY

\begin{tabular}{ccc}
\hline & Clusters 3(Factor 3): Granulation Efficiency \\
\hline S/N & Variable description & Factor loading \\
\hline 13 & Enhanced efficiency fertilizer & 0.619 \\
23 & Granulometric content & 0.561 \\
27 & Granulation method & 0.694 \\
\hline
\end{tabular}

The third factor is a trio comprising Enhanced efficiency fertilizer, Granulometric content and Granulation method. They have middling factor loadings suggesting that their role is moderately influenced.

\begin{tabular}{ccc}
\multicolumn{3}{c}{ TABLE V: AgRICULTURAL NATIONAL POLICY } \\
\hline \multicolumn{3}{c}{ Clusters 4(Factor 4): Agricultural National Policy } \\
\hline S/N & Variable description & Factor loading \\
1 & Agricultural national policy & 0.894 \\
\hline
\end{tabular}

There is also a lone factor creatively labeled Agricultural national policy. It is a lone factor that is a major factor of its own. Its factor loading is very substantial. Every country's agricultural national policy differs, and this is also what needs to be considered in the manufacture of chemical fertilizer granulating machine.
TABLE VI: BIOPHYSICAL ELEMENTS

\begin{tabular}{ccc}
\hline \multicolumn{3}{c}{ Clusters 5(Factor 5): Biophysical Elements } \\
\hline S/N & Variable description & Factor loading \\
17 & Natural deposits & 0.626 \\
24 & Amount of rainfall & 0.598 \\
\hline
\end{tabular}

Finally, we encounter a dual factor creatively labelled Biophysical element. They were labeled so because an important obstacle to promoting fertilizers demand is the diversity of biophysical conditions across the country. The amount of annual rainfall differs from north to south. Also, natural deposits vary from place to place.

\section{CONCLUSION}

The results established five principal factors which were creatively labeled. Results obtained by KCC suggested that judges ranking were consistent. Also, PCA was indicating parsimony in data reduction from 32 variables to mere five. The most influential variable by its factor loading of 0.894 is Agricultural national policy. This has helped in discerning similarities in dissimilarities. The Rj totals were arranged in increasing order of sequence. R1, R2, R3...Rn, and this helped to determine the order of importance of the variable as ranked by the thirteen Judges. Five clusters of variables were generated from the study with the aid of statistical XL software. The general and latent implications and results of each cluster which are creatively labeled with regards to the design, manufacture and usage of chemical fertilizer granulating machine have been highlighted and the study has established inter correlations among the variables. Kendall Coefficient of Concordance provided a merit order sequentiality of these variables. A null hypothesis claiming that the ranking of the range of factors by thirteen (13) Judges is discordant was rejected. The results obtained from the study are not only figure-hugging but also tight-fitting.

\section{REFERENCES}

[1] Ammani, A.A., Alamu, J.F. and Kudi, T.M. (2010) Effects of Fertilizer Liberalization on Maize Production in Nigeria. Journal of Development and Agricultural Economics, 2(11): pp. 401-405.

[2] I.A. Daniyan1, A.M. Omokhuale1, A.A. Aderoba1, O.M. Ikumapayi1 and B.A. Adaramola (2017), Development and performance evaluation of organic fertilizer machinery September Cogent Engineering 4(1).

[3] Fayed, M. E. and Otten, L. (Eds) (1984) Handbook of Powder Science Technology, Size Enlargement Methods and Equipment, pp. 230-344.

[4] Food and Agriculture Organization of the United Nations, FAO (1975) The state of food and agriculture 1974 world review by regions population, food supply and agricultural development Rome, Italy.

[5] Capes C. E. (1982) Particle Size Enlargement, Elsevier Scientific Publishing Company, New York.

[6] Ezeokonkwo, J. C. (2011) Engineering Properties of NPK Fertilizer Modified Soil. Journal of Emerging Trends in Engineering and Applied Sciences (JETEAS) 2 (6): 962-966.

[7] Phillip, D., Nkoya, E., Pender, J. And Oni O.A. (2009) Constraints to Increasing Agricultural Productivity in Nigeria: A Review. Nigeria Strategy Support Program (NSSP) Background Paper No. NSSP 006, Abuja, Nigeria.

[8] Deb Ratul, Ahmed Abdul Baquee. 2013. Pellet and pelletization techniques: A critical review. International Research Journal of Pharmacy; 4(4): 90-95. 
[9] Sochon R. P. J., S. Zomer, J. J. Cartwright, M. J. Hounslow, and A. D. Salman. 2010. The variability of pharmaceutical granulation.Chemical Engineering Journal 164: 285 - 291.

[10] Ekejiuba, A.I.B., 2017. Real-Time Monetization of the Flared Associated Stranded Natural Gas in Nigeria: Quantitative Analysis and Qualitative Values. The International Journal of Science \& Technology, Vol. 5 Issue 8, pp. 96-98. 